\title{
Investigating the Relationship Between Perceived Community Safety and the Public's Attitudes Towards the Treatment of Youth Offenders in New Zealand
}

\author{
Sean McArdle, Ian Lambie, and Sarah Miers \\ School of Psychology, The University of Auckland, Auckland, New Zealand
}

\begin{abstract}
W hile opinions on what should be done with youth offenders vary from person to person, perceived levels of safety and fear of crime have been linked to more punitive attitudes towards crime and punishment. Qualitative methods were employed to explore the attitudes and opinions of members of the New Zealand public with varying levels of community safety in respect to the treatment of youth offenders. Results indicate those who identified as lowest in levels of safety were more punitive in their opinions, though they also expressed a firm desire for progressive treatment options such as rehabilitation and taking preventative action. Those who felt the safest in their community were less likely to be punitive in their opinions towards youth offenders.
\end{abstract}

Keywords: youth offending, public opinion, punitiveness, thematic analysis

Similar to other liberal democracies, youth crime has been and still is an area of great concern to New Zealanders. Given the visibility of youth crime on television and the recurrent presence of high profile cases in media discourse, many members of the public have developed strong opinions on youth crime and how youth offenders should be dealt with by the judicial system. International studies have shown attitudes held by the public can be influenced by psychosocial factors such as fear, especially when it comes to attitudes towards crime and punishment (Maruna \& King, 2009; Spiranovic, Roberts, \& Indermaur, 2012). Further studies have determined that these attitudes and opinions have the potential to influence political policy, as governments make policies that aim to reflect public sentiments (Roberts, 2004; Schwartz, Guo, \& Kerbs, 1992). Policy based on perceived public opinion has economic, political, social, and societal consequences. It is therefore important to gauge the public's attitudes towards youth offenders in order to see whether it is in line with current political agendas and trends. To date, no studies in New Zealand have been conducted to determine the extent to which feelings of unsafeness influence punitive and rehabilitative sentiments towards youth offenders. This area of investigation is important, as fear of crime may influence the endorsement of punishment oriented government policies, which have been shown to be largely ineffective at reducing youth crime. Furthermore, a greater insight into the thoughts of the NZ public and opinions regarding the treatment of youth offenders is needed in order to measure the public's support for specific treatment options.

\section{Background}

Crime and law and order have, in the last 10 years, become a major issue of importance for NZ citizens. Previously, it was not considered to be of significance; offender rehabilitation and reducing rates of incarceration were top priority, and the penal policies aimed to do this were developed by criminal justice experts based on well researched evidence (Pratt, 2007). By the late 1990s, media and political spheres took a 'tough on crime' stance, where phrases such as 'life means life', 'zero tolerance', and 'truth in sentencing' were commonplace (Pratt \& Clark, 2005).

The election in 2002 saw politicians on both sides of the political fence try and gain public support by adopting a 'tough on crime' stance. Around this time, pressure groups such as the Sensible Sentencing Trust began to form and gain momentum (Bartlett, 2009; Pratt \& Clark, 2005). 
Claiming they represented the 'voice of the ordinary Kiwi', the groups actively campaigned for harsher treatment of offenders, adding to the pressure faced by politicians to appease the public's perceived want for a tougher approach (Pratt \& Clark, 2005).

More recent reforms and legislation have created tougher sentencing practices for persistent youth offenders, widened the Youth Court's jurisdiction to include 12and 13-year-olds, and continued to place 17-year-olds outside the realm of the Family Court dealings. These amendments and policies were not made based on sound empirical evidence, or with the intention of reducing recidivism and incarceration rates. They were made on what was understood to be 'public opinion', in an attempt to secure votes (Pratt \& Clark, 2005). The 'tough on crime' discourse and the airtime granted to groups like the Sensible Sentencing Trust placed added pressure on politicians and the government alike. This materialised in the way of more punitive programs and fewer cost-effective, empirically based, successful programs. Consequently, the treatment of youth offenders has been contrary to what the scientific evidence suggests. Given we have moved past a 'What works?' phase and are now asking 'What works best?' in dealing with youth offenders, this mismatch between government policies and evidence-based practice is of great concern.

\section{Public Attitudes Towards Youth Offenders}

Studies concerned with public attitudes towards youth offenders are infrequent in the literature, with the majority of studies focusing on adult populations. Despite this, there are a number of studies, with varying methodologies, which all suggest that the public hold rehabilitative and progressive attitudes in relation to youth offenders. Concerned with the recent trend in the U.S. juvenile justice system towards more punitive measures, Piquero and Steinberg (2009) conducted a study to determine whether the public actually favoured these responses over rehabilitation. Respondents from four different states in the United States $(N=2,282)$ were presented with a hypothetical situation whereby incarceration and rehabilitation were of equal effectiveness. Each participant's willingness to pay (WTP) for one policy over the other was then gauged in order to identify a 'true' preference. The results showed the public were more willing to pay for rehabilitation than incarceration, and these results were constant across all four states. Piquero, Cullen, Unnever, Piquero, and Gordon (2010) also found a preference for rehabilitation in their U.S. study, which set out to measure support for juvenile rehabilitation, and whether there was an age considered 'too late' to be reformed. The results revealed a public that strongly supported juvenile rehabilitation. Participants also displayed optimism that youthful offenders of all ages could be reformed, suggesting even those youths who verge on adulthood could, and should, be rehabilitated.
With the goal of gaining a more accurate view of public attitudes towards youth offending, Scott, Reppucci, Antonishak, and DeGennaro (2006) individually assessed almost 800 adults. Unlike previous research, which tended to ask more general questions in the hope of understanding public opinion, this study used very specific questions involving video material and photos of individuals involved in serious youth crime. The study also explored participants' general attitudes about processing youth in adult criminal courts. The major finding was that the public had a strong preference for treating youth more leniently than adult offenders. Furthermore, little support was found for recent statutory reforms that were aimed at taking a tougher approach to youth offending. The results indicated that participants recognised the immaturity of adolescents and the relationship between youth age and criminal responsibility, and further challenged the assumptions that the public supported more punitive policies for youth offenders.

There have only been two studies to date in New Zealand exploring the public's attitudes towards offenders. The first focused on the public's view of sex offenders and how these views were developed (Thakker, 2012). The second focused on students' attitudes to crime and punishment in general and looked specifically at levels of punitiveness (Rowe, 2013). Only the latter study will be discussed here given its relevance to the current study.

Rowe's (2013) study aimed to partially fill a void in the literature on the public attitudes to crime in New Zealand. It should be noted that this study used a sample of university students, which is not representative of the general public's opinion, though the results are still relevant as this is the only study of its kind conducted in New Zealand. Students were required to complete a detailed survey regarding a number of different phenomena - experiences of crime, perceived safety levels, other negative life experiences, concerns about different types of crime, sanctions for different criminal behaviours, and support for capital punishment (non-inclusive list). The results were novel, as the questionnaire probed deep into the students' attitudes to crime, resulting in a number of interesting finds. The first was that the public (i.e., students) considered crime an issue but not an overwhelming one, being weighted in line with other negative life experiences such as being involved in a car accident. Second, attitudes towards offending were not categorised as being highly punitive, as other factors were considered of greater importance than punitive sanctions (e.g., restitution for victims). Third, and most alarmingly, the survey found $42.9 \%$ of students were in favour of the death penalty when it came to some crimes - murder being the crime most often cited (67.4\% of those who said 'Yes' to capital punishment). Lastly, the overarching theme of the survey indicated that these students were less concerned about the risks of crime, though their reactions to crime in regards to punitiveness were less clear-cut. 
The above studies suggest that the majority of the public do not hold punitive sentiments towards youth offenders and are more supportive of rehabilitative strategies. The current study, however, is concerned with people's safety perceptions and how these may influence attitudes towards youth offenders. The following literature will explore how fear of crime influences such attitudes.

\section{Fear of Crime and Attitudes to Crime and Punishment}

Mechanisms behind public attitudes towards crime and punishment are well studied; researchers have been particularly interested in a few key variables (age, gender, and race/ethnicity). Despite this, international studies have reported conflicting and unclear results (see Wood \& Viki, 2004, for a detailed discussion). The inconsistency between demographic variables and the public's attitudes to punitiveness has led some researchers to suggest other factors and mechanisms by which opinions are influenced must be at play. Wood and Viki (2004) propose that differences in attitudes to crime may be mediated by psychosocial factors. For example, the older generation's attitudes to crime may be mediated by the experience of fear and perceived vulnerability to crime (Wood \& Viki, 2004). Allen (2002) also concludes this could be the case, postulating that fear of crime could be an important mediating factor between socio-demographic groups and attitudes to youth crime. As with the literature on general public attitudes toward youth offenders, studies concerning the role fear plays in influencing these attitudes have not been conducted in New Zealand. This could be due to the public perception of New Zealand as a safe place to live, and high levels of public fear have not been identified as serious social issues in need of remedy. Consequently, the following literature will include relevant research on attitudes towards youth as well as adult offenders, conducted in countries outside of New Zealand.

The weight of evidence from international studies favours the idea that fear of crime is a significant and strong predictor of punitive attitudes (Applegate, Cullen, \& Fisher, 2002; Brookman \& Wiener, 2017). That is, individuals who express a greater fear of crime are more likely to hold punitive views on sentencing and offender treatment. These findings are not uncommon and are found to be present in countries that differ in crime rates, political stability, levels of economic uncertainty, and social attitudes. Fear of crime has been identified as a strong predictor of punitive attitudes in both the Czech Republic and Florida (Costelloe, Chiricos, Buriánek, Gertz, \& Maier-Katkin, 2002), in Greece (Zarafonitou, 2011), England and Wales (Hough, Lewis, \& Walker, 1988; Hough \& Moxon, 1985), and the United States (Langworthy \& Whitehead, 1986). However, some studies have failed to replicate these results (see Ouimet and Coyle, 1991).

To date, only a limited number of studies have looked specifically at the role fear plays in attitudes towards juvenile crime and justice. Schwartz et al. (1992) examined the relationship between certain variables (e.g., education, political views, demographics, and fear of victimisation) and the public's attitudes towards the treatment of young offenders in the United States. What this study found was that as fear increased, support for all punitive-oriented options increased, suggesting fear of being the victim of juvenile crimes resulted in more punitive attitudes towards youth offender treatment. In contrast, Baron and Hartnagel (1996) found that although a third of respondents in their study identified themselves as afraid, fear of crime had no consistent effect on punitiveness. These inconsistent results indicate research is needed in this area in order to determine whether the relationship between fear and punitiveness toward youth crime holds over international borders.

\section{Rationale for the Study}

The available literature on the public's attitudes toward youth offenders indicate that the public are less punitive than political and media discourse seems to assume. Furthermore, there is considerable support for rehabilitative and community-based approaches that have been shown to be more successful than punitive-oriented approaches (Scott, 2008). However, to date, there have been no studies conducted in New Zealand looking specifically at the relationship between fear of crime and the public's attitudes toward youth offenders. Two studies have been conducted overseas (Baron \& Hartnagel, 1996; Schwartz et al., 1992), producing contradictory results. The need for further investigation is evident. International studies previously mentioned have shown fearful individuals hold more punitive sentiments towards offenders, though studies in this area have not been conducted in New Zealand. Members of the public who hold punitive sentiments are more likely to be part of, or supportive of, pressure groups that advocate for harsher treatment of offenders; for example, the Sensible Sentencing Trust. History shows that these groups hold sway with the government and can influence specific public policies that deal with offenders in expensive and ineffective ways. It is therefore important to look at individuals with varying levels of perceived community safeness and their attitudes towards youth offenders.

Research on understanding public opinion will allow the evidence to dictate whether the government has been justified in implementing recent policies on the basis of public desire. Depending on outcomes, studies in this area may also provide a mandate to implement programs that work in reducing recidivism, as opposed to what the government think the people want. The fact that policy making in New Zealand has in the past been driven by populist politics and has proceeded in the absence of any systematic analysis of the public's opinion raises concern. Consequently, the need for scientific research to guide policy in this area, particularly youth justice, is timely. 


\section{Method}

Participants

The data used in the current study were drawn from a larger study investigating the wider NZ public's attitude towards youth offenders. In total, 832 demographically diverse New Zealanders participated in the original study. Respondents were aged 18 to $80+(M=55.28, S D=15.94)$ and females were slightly over represented (58.08\%) compared to males $(41.92 \%)$. Self-indicated ethnicity was diverse, though the vast majority identified as 'New Zealand European' (87.69\%), 6.97\% as Maori, $1.74 \%$ as Chinese, $0.87 \%$ as Samoan, $0.62 \%$ as Indian, $0.12 \%$ as Cook Island Maori, $0.12 \%$ as Tongan, $0.12 \%$ as Niuean, and $7.84 \%$ as 'Other'.

The present study used a subset of these data, specifically those who rated themselves as feeling 'very safe', 'unsafe', and 'very unsafe' in their community $(n=174)$. Of the 174 participants, 103 were female (59.20\%), 69 were male $(39.66 \%)$, and 2 were unknown (1.15\%). Respondents were aged $18-80+(M=55.93, S D=15.30)$. The vast majority identified as 'New Zealand European' (80.32\%), 6.38\% as Maori, $1.60 \%$ as Samoan, $9.04 \%$ as 'Other', and $2.66 \%$ left this question blank. The above demographic information indicates a strong likeness with the larger sample pool from which it was drawn, suggesting a representative sample was obtained. In terms of levels of fear, 138 individuals identified as feeling 'very safe' in their community (79.31\%), 32 as 'unsafe' (18.39\%), and 4 as 'very unsafe' $(2.30 \%)$.

\section{Recruitment}

Ethics approval for the study was obtained from the University of Auckland Human Participants Ethics Committee. Following this, a sample of 5,000 potential participants was randomly selected from the NZ electoral roll to try and ensure a representative sample. Potential participants were invited by mail to complete the questionnaire online or by hand and returned in hard copy; reminders were not sent. Participants had a maximum of 21 weeks to complete and return the questionnaire. Research indicates using mixed modes for participant responding (e.g., electronic and pen/paper) does not distort results or influence response rates (Rübsamen, Akmatov, Castell, Karch, \& Mikolajczyk, 2017). Electronic questionnaires were copied and therefore still retain any grammatical and syntactical errors. The questionnaire was created online using the web survey development tool SurveyMonkey, which was linked to via a website purpose built with information for participants: www.youthoffenderstudy.com.

\section{Procedure}

As described earlier, this current study focused exclusively on those participants who rated themselves as feeling 'very safe', 'unsafe', and 'very unsafe' in their community. This was determined by the question 'How safe do you feel in your community?', with a selection of five categories: very safe $(22.52 \%)$, safe $(57.77 \%)$, neutral $(14.75 \%)$, unsafe $(4.53 \%)$, and very unsafe $(0.61 \%)$. Of these, only the categories of interest are used in the current study; very safe, unsafe, and very unsafe. Participants in the unsafe and very unsafe categories were grouped together, given the small number of respondents. Safe and neutral categories were removed from the sample as extremes of the fear spectrum were desired for comparative purposes. All participants were asked 'What do you think could be improved in the way New Zealand deals with youth offenders?' The unit of analysis was the qualitative response to this question: their attitude towards youth offenders.

\section{Data Analysis}

Questionnaire data were analysed by flexibly applying thematic analysis, a method for identifying, analysing, and reporting patterns across datasets, which is suited to investigating under-researched areas (Braun \& Clarke, 2006). Given language was not specified on the survey, the one response given in Te Reo Maori was translated internally so it could be included in the data analysis.

The data were read and reread a number of times, and then coded by sorting into themes and subthemes that were reviewed and refined throughout. The initial coding system was primarily inductive or 'bottom up', where codes and themes were developed from the data content (Braun \& Clarke, 2006). There is also a deductive component to the data analysis as the process of coding and interpretation was influenced by the original aims and objectives, as well as the themes identified in the data. The coding of opinions focused on both the semantic/explicit content of what participants wrote and on the interpretive level/latent meanings in the data (i.e., underlying ideas and assumptions of semantic meanings; Braun \& Clarke, 2006).

Coding consistency checks as described by Thomas (2006) were carried out during this process. Once initial coding of the data was completed, an independent coder was given the developed categories and descriptions of each category without the raw text attached. The coder was then given a sample of the raw text (previously coded by the initial coder) and asked to assign the data to the previously developed categories. The extent to which the second coder allocated the same text units to the initial categories was then checked, and discrepancies were reviewed and discussed. Following consensus, the 'key' themes were clearly identified and the scope and content established. Concise names were given to themes that clearly captured their essence and content, and descriptive frequencies were used as they provide a useful summary of the theme prevalence.

\section{Results}

Participants' responses were organised into six final themes (refer to Table 1 for frequencies). These themes were: prevent the offending from happening in the first 


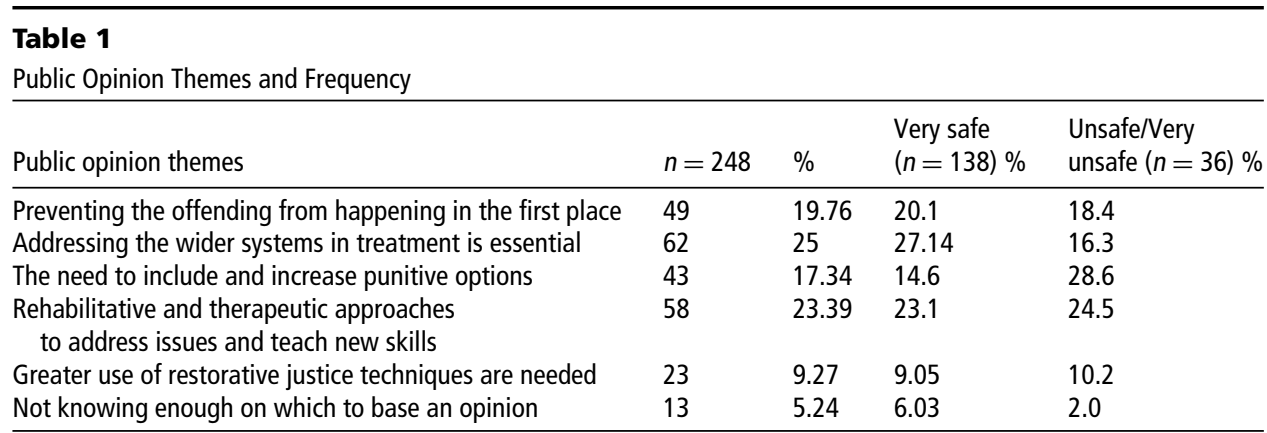

place, address the wider systems of the youth, the need for more punitive options, rehabilitation and therapeutic approaches, greater use of restorative justice techniques, and not knowing enough on which to base an opinion. These six themes form the basis of discussion and shall each be developed with illustrative examples. Prevalence of themes shall also be expressed in percentages for the overall sample, and specifically in relation to the two groups 'very safe' and 'unsafe' with 'very unsafe'. Individual responses were often included in more than one theme as a result of the study design and to capture the complex nature of public opinion.

\section{Prevent the Offending from Happening in the First Place}

One of the most prominent themes was an endorsement of preventative action in dealing with youth offenders. Opinions on preventing the offending in the first place, as well as addressing the issues early, were evident throughout the data, at both semantic and latent/interpretive levels. Of the 174 respondents, 49 (28.2\%) indicated that they thought preventative action would be an improvement on the current treatment of youth offenders. There was considerable acknowledgment among those who suggested preventative action that the road to offending starts at a young age, and the need to intervene early is critical. For example: 'Try to put things in place to stop them offending in the first place.'

Of those who suggested early intervention strategies, the most commonly cited reason was aimed at the family and parents, and included support and education; for example: 'There needs to be more intervention into dysfunctional families at an early stage, before offending starts.'

Both the very safe group and unsafe/very unsafe group expressed desire for preventative action at similar rates ( $20.1 \%$ and $18.4 \%$ respectively).

\section{Addressing the Wider Systems in Treatment is Essential}

The most prominent theme to emerge from the data was the suggestion to address and remedy the systemic factors that are seen to be increasing the chances of a youth offending (35.6\%). Respondents noted that issues in the wider context, often outside the control of the youths, play a major role in leading them down a pathway to crime. There was a wide variety of factors that the respondents thought were in need of addressing. These included drugs and alcohol, parental incompetence, family violence, gang culture, poverty, job shortages, and unemployment, as illustrated in these quotations: 'More focus on root causes of youth offending: poverty, inequality, familial violence, racism. Focus on breaking the cycle of violence'; 'I believe we need meaningful work opportunities for youth. Local communities need to set up places that are safe and provide employment to youth to give them skills and confidence.'

A large portion of these respondents thought the family environment and parenting were major issues in need of addressing: 'I'm not a professional but I would like to see more support for families. Rather than a punitive approach, look at why young people are offending. I'm certain stronger NZ families would result in less offending.'

Members of the very safe group were more likely to suggest an option that addressed systemic factors to improve the way New Zealand deals with youth offenders $(27.14 \%)$, whereas in the unsafe/very unsafe group, this theme was not as evident (16.3\%).

\section{The Need to Include and Increase Punitive Options}

Taking a more punitive approach to dealing with youth offenders was favoured by $24.7 \%$ of the sample. Some explicitly stated a preference for various punitive options such as longer prison sentences. For example, one respondent suggested: 'Harsher sentences. We seem to be very lenient and it just comes back to bite us when the youth reoffends.'

Other suggested options that fell under the punitive theme included increased monetary fines, corporal punishment, eugenics, allowing parents to physically discipline their children, and limiting the rights of youths. The most commonly suggested punitive options were boot camps and/or military training; for example: 'Boot camp for three months with some good ole discipline, especially boys!'

Other respondents were more ambiguous as to the method of punishment, though still expressed the same desire to get tougher on youth offenders: 'Get rid of those people who believe they can change a youth offender by counselling, this does not work. Only when the offender 
serves punishment do they realise their crime has a consequence on them.'

Punitive options were considerably more common in the unsafe/very unsafe group compared with the very safe group ( $28.6 \%$ and $14.6 \%$ respectively). This theme was also the most common theme to emerge from the unsafe/very unsafe group.

\section{Rehabilitative and Therapeutic Approaches to Address Issues and Teach New Skills}

It was clear throughout the data that there was a strong preference for rehabilitative approaches in dealing with youth offenders. Responses suggesting a more rehabilitative approach were second highest, and comprised a third of all responses (33.3\%). Many respondents cited education and the teaching of new skills as crucial steps in rehabilitating youth offenders. For example: 'Education programs - teaching young offenders to read and write, apprentice programs, sports programs.' Another respondent noted: 'I would like to see more "training camps" with trained counsellors, not necessarily "boot camp", but with motivational training, physical challenge and confidence building. Also help to obtain paid employment for example, education, work experience, grooming of appearance etc.'

A number of respondents also expressed the need for counsellors to be involved in the treatment of youth offending. Some went a step further to comment on the need for increased competency and availability of counsellors, which is exemplified by the following quote: 'Counselling MUST be fully specifically trained and experienced in working with youth offenders.'

Interestingly, both the very safe and unsafe/very unsafe groups had a similar proportion of respondents express a desire for rehabilitation ( $23.1 \%$ and $24.5 \%$ respectively).

\section{Greater Use of Restorative Justice Techniques are Needed}

Restorative justice was proposed as an improvement to the way New Zealand deals with youth offenders by $13.2 \%$ of respondents. The majority of these described victim restitution as important, as illustrated by the following quotations: 'Offenders should have to pay back to the victim money, property stolen, and should be made to face and apologise to the victim. They need to know that there is a personal side to their offending', and 'NZ needs more rehabilitative programs and restorative justice programs in place. The youth criminal needs to see the impact of their choices on both the victim and society as a whole.'

Other respondents expressed a want for reparative sentences, such as monetary restitution to individual victims, and community service: 'They need to pay $\$ \$$ to pay back the community somehow.' Another noteworthy response was: 'Make them accountable by working off their debts to society - that is, actual hard work - and make them pay back money (all of it) to victims, that is the value of stolen property.'
Respondents in both groups indicated a preference for restorative justice at similar rates; $9.05 \%$ of very safe and $10.2 \%$ of unsafe/very unsafe participants.

\section{Not Knowing Enough on Which to Base an Opinion}

A number of participant responses (7.5\%) indicated they did not know what to suggest for improvements in treating youth offenders. Responses such as 'I don't know' were the most common in this theme. Not knowing due to a lack of knowledge of current practice was also prominent. A typical response was: 'Don't actually know how youth offenders are dealt with in NZ, so can't comment'; or 'Don't know enough about it to comment.'

Respondents in the very safe group stated they 'didn't know' three times as often as the unsafe/very unsafe group (6.03\% and $2.0 \%$ respectively).

\section{Participants Falling Under More Than One Theme}

It is important to note that participant responses did not always fall discretely under a single theme. The study's ability to accommodate multiple opinions resulted in a number of responses that fell under more than one theme. Here is a response that fell in both the rehabilitation and punitive option themes: 'A better balance combining punishment and rehab as offenders both young and old must be punished for crimes; however, rehab should come as part of the program.'

Of the 174 respondents, $113(64.9 \%)$ gave a response that fell under a single theme, $48(27.6 \%)$ were coded under two themes, and $13(7.5 \%)$ were coded under three themes.

\section{Discussion}

In summary, the most common opinions to emerge from the respondents who felt unsafe/very unsafe were (in order of most common): the need to include and increase punitive options for dealing with youth offenders, rehabilitative and therapeutic approaches, preventing the offending from happening in the first place, addressing the wider systems, greater use of restorative justice techniques, and not knowing enough to have opinion.

For the very safe group, the most common responses were those that indicated a need to address the wider systems: rehabilitative and therapeutic approaches, preventing the offending from happening in the first place, including and increasing punitive options, greater use of restorative justice techniques, and not knowing enough to have an opinion. As noted above, NZ residents who felt unsafe in their community were more likely to suggest punitive options for improving the treatment of youth offenders. However, a sizeable portion of respondents also expressed the opinion that rehabilitation and therapeutic approaches need to be included in treatment. The unsafe/very unsafe group also expressed firm support for other progressive options, highlighting the complexity of public attitudes. 
The following sections of the discussion will talk about the main findings in relation to the international literature specific to fear of crime and punitiveness, and also more broadly to provide context to the findings from respondents. It will then conclude with a discussion regarding the potential implications for policy makers.

Given the relative absence of international studies that have looked at how perceived levels of safeness influence attitudes towards youth offender treatment, identifying where these results fit within the wider literature becomes problematic. Despite this, similarities and differences can be drawn between a number of existing studies. The findings of this study suggest that level of community safety has a marked impact on what opinions people will hold with regards to youth offender treatment. Specifically, those who felt unsafe/very unsafe more commonly expressed an opinion punitive in nature. Studies looking at fear of crime and level of punitiveness in general (not specific to youth offenders) have had similar findings. Results from the current study are in line with a number of international studies that found fear of crime was associated with increased punitiveness towards adult offenders (Costelloe et al., 2002; Hough et al., 1988; Hough \& Moxon, 1985; Langworthy \& Whitehead, 1986; Zarafonitou, 2011). With respect to fear of crime and attitudes towards youth offenders, the results of the current study are somewhat in line with those of Schwartz et al. (1992), who found fear of crime influenced punitive attitudes to dealing with youth offenders. Baron and Hartnagel (1996) in contrast, found fear of crime was not a consistent or significant predictor of punitiveness towards youth offenders. Significance aside, our findings in a general sense support the relationship between fear of crime and punitive attitudes for youth offenders in New Zealand.

In the current study, those who identified as unsafe/very unsafe were more punitive in their attitudes, though to take this in isolation would ignore more nuanced findings and implications. Respondents with varying degrees of perceived safety also had strong preference toward rehabilitation of youth offenders. This finding suggests that the NZ public may be much less punitive than politicians and media assume, a finding consistent with Rowe's (2013) study conducted in New Zealand.

Around $20 \%$ of both the very safe group and the unsafe/very unsafe group had the opinion that preventing offending from happening in the first place or intervening early was of importance further. This early intervention approach, specifically supporting dysfunctional families and parents, is supported by a wealth of research (see Sexton \& Alexander, 2002). Further, respondents in both groups identified a number of what the literature refers to as 'risk factors' (Loeber \& Farrington, 1998) as targets for improving the treatment of youth offenders. These included family violence, drugs and alcohol, poverty, parental incompetence, unemployment, and gang culture (to name a few). This is consistent with a growing body of literature that shows interventions that target a multitude of risk factors, including those previously mentioned, are more effective in reducing recidivism rates (Caldwell \& Van Rybroek, 2013; Lipsey, 2009; Lipsey \& Cullen, 2007). Specifically, quality of parenting and the family environment were two areas which both groups thought were in need of addressing. This is consistent with the support for early interventions aimed at families and parents (Sexton \& Alexander, 2002). We know from international studies that interventions such as Functional Family Therapy (FFT; Alexander \& Parsons, 1982) and Multisystemic Therapy (MST; Huey, Henggeler, Brondino, \& Pickrel, 2000) have been successful in reducing recidivism rates (Caldwell \& Van Rybroek, 2013), largely because they specifically work with the wider context (i.e., family and parents).

By far the most common suggestion that fell under the punitive theme was the enthusiasm and support for boot camps and military training. Given its popularity, it is possible that offenders' age may have acted as a mitigating factor as more severe sanctions were less commonly proposed. International research has repeatedly shown these sorts of 'quick fix' boot camp programs do not work at reducing recidivism rates (Benda, 2013), and in some cases they have increased recidivism (Lipsey \& Cullen, 2007).

It is somewhat surprising that favour for restorative justice was so low (very safe $-9.05 \%$ and unsafe/very unsafe $-10.2 \%$ ), given its success in New Zealand and abroad (Ministry of Justice, 2014) and the profound contributions New Zealand has made to the practice of restorative justice (Zehr, 2005). To account for the relatively low prevalence of this theme it is hypothesised that the public may be under the impression that restorative justice is not effective in treating youth offenders. Alternatively, there may be a more general lack of understanding as to what restorative justice entails. International studies have provided substantial evidence that the principles of restitution and community service appeal strongly to the public (Gandy, 1978; Lee, 1996), though we failed to find this in the current study.

The main findings of this study suggest fear of crime is not as strong an influencer of punitive attitudes when it comes to youth offenders as the international literature suggests is the case for adult offenders. While the results are not in contrast to the large corpus of literature illustrating a relationship between fear of crime and punitive attitudes and sentiments with adults, it does draw into question the strength of this relationship with regard to youth offenders. A sizeable portion of those with low levels of perceived safety endorsed alternatives to punishment which were (as will be described later in the discussion) highly insightful and in line with best practice methods. This raises an interesting line of inquiry for the field moving forward. How strongly does fear of crime influence punitive attitudes for youth offenders? How does this compare to adult offenders, and what variables may moderate and temper this relationship? Further research is necessary to sufficiently answer these questions. 


\section{Implications}

Any implications for policy development must be taken in light of the study's limitations. Although the sample these participants were taken from was diverse and representative, the sample was self-selected. It is possible that people who participate in these types of surveys have particularly strong views and opinions; therefore, we cannot claim those who took part were truly representative of the NZ population. Moreover, on reflection, the location of the question 'What do you think could be improved in the way New Zealand deals with youth offenders?' in the questionnaire may have influenced the results. It is possible the previous questions regarding various treatment and management options may have provided unknowing participants with ideas for improvements. If this question was asked in isolation or before questions which listed management options, the results may have been different; there may have been more who answered 'I don't know'.

Broadly speaking, a large portion of the sample expressed a desire for early intervention/prevention programs, rehabilitative and therapeutic approaches, and targeting wider systems when treating youth offenders. This finding on its own holds implications for future policy. The international literature provides ample evidence that should incentivise policy makers to adopt a more progressive approach to youth offender treatment. For example, an early intervention/prevention approach has potentially huge economic benefits both in the short and long term (Yoshikawa, 1994). A large number of those in the adult correctional system began offending at a young age, and currently keeping a person incarcerated costs approximately NZ\$97,090 a year (Department of Corrections, 2012). Even more startling, the NZ Treasury estimated the cost of crime was approximately $\$ 9.1$ billion from 2003/04 (Roper \& Thompson, 2006) and there have been no indications that this cost has dropped in subsequent years. Research is showing that interventions at early stages are promising - specifically, early family support and education (Yoshikawa, 1994); two suggestions commonly noted by respondents of both groups.

It is also important to note that these programs can be some of the most cost effective available. Cost-benefit analysis in the United States shows that MST, by reducing delinquency and incarceration, saves an estimated $\$ 31,661$ to $\$ 131,918$ per participant (U.S. dollars), and FFT saves taxpayers anywhere between $\$ 14,149$ to $\$ 59,067$ per participant (Aos, Phipps, Barnoski, \& Lieb, 2001). More research conducted in New Zealand concerned with costbenefit analysis of these programs is needed to determine the specific monetary benefits, though the proven efficacy and ballpark cost savings make these programs a rare 'win-win' situation for policy makers.

\section{Conclusion}

At a minimum, these findings challenge the assumption that New Zealanders want a 'tough on crime' approach to youth offenders. The sheer quantity of progressive responses from both groups support the idea that individual agency, more commonly ascribed to adult offenders, is largely ignored in favour of looking at the larger picture. This study reveals the public have an understanding that responsibility does not fall on the youth offender but on society as a whole, and that offending has more to do with care and protection issues than it does personal culpability. With this in mind, the current age-determined safeguards in place to protect the rights of children who are the victims of circumstance are both appropriate and necessary. The NZ youth justice system, however, while praised internationally, often deals with 'young persons' aged between 14 and 17 using a 'justice' response rather than a 'welfare' response, and continues to place 17-year-olds outside the realm of the Family Court. This response, when looked at objectively, places the blame and responsibility on the youth regardless of context and has unsurprisingly been criticised by a number of workers in the field (Lambie, Ioane, \& Best, 2014). Thus, politicians may be misreading public opinion. In conclusion, this study reveals the NZ public to be far less punitive than the media and political spheres assume, and fear of crime to have a mild influence on attitudes towards youth offender treatment. The NZ public have a deep insight into the problems in need of addressing and their opinions reflect a strong understanding of youth offending's multifaceted aetiology. While it is not possible to make generalisations, given New Zealand's unique social, cultural, economic and political context, and the qualitative methodology used, it is hoped this study acts as a useful starting point for further research in the area and for the development of empirically based public policy.

\section{References}

Alexander, J., \& Parsons, B.V. (1982). Functional Family Therapy. Pacific Grove, CA: Brooks/Cole Publishing.

Allen, R. (2002). 'There must be some way of dealing with kids': Young offenders, public attitudes and policy change. Youth Justice, 2, 3-13.

Aos, S., Phipps, P., Barnoski, R., \& Lieb, R. (2001). The comparative costs and benefits of programs to reduce crime. Version 4.0. (Report No. 01-05-1201). Washington, DC: Washington State Institute for Public Policy.

Applegate, B.K., Cullen, F.T., \& Fisher, B.S. (2002). Public views toward crime and correctional policies: Is there a gender gap? Journal of Criminal Justice, 30, 89-100.

Baron, S., \& Hartnagel, T. (1996). 'Lock'em up': Attitudes toward punishing juvenile offenders. Canadian Journal of Criminology, 38, 191-212.

Bartlett, T. (2009). Public influences on penal and sentencing policy from 1999 to 2008 (Unpublished master's dissertation). Victoria University of Wellington, Wellington.

Benda, B. (2013). Rehabilitation issues, problems, and prospects in boot camp. New York, NY: Routledge. 
Braun, V., \& Clarke, V. (2006). Using thematic analysis in psychology. Qualitative Research in Psychology, 3, 77-101.

Brookman, R.P., \& Wiener, K.K. (2017). Predicting punitive attitudes to sentencing: Does the public's perceptions of crime and Indigenous Australians matter? Australian \& New Zealand Journal of Criminology, 50, 56-77.

Caldwell, M.F., \& Van Rybroek, G. (2013). Effective treatment programs for violent adolescents: Programmatic challenges and promising features. Aggression and Violent Behavior, 18, 571-578.

Costelloe, M.T., Chiricos, T., Buriánek, J., Gertz, M., \& MaierKatkin, D. (2002). The social correlates of punitiveness toward criminals: A comparison of the Czech Republic and Florida. Justice System Journal, 23, 191-220.

Department of Corrections. (2012). Department of Corrections 2012/2013 Annual Report. Wellington, NZ: Author.

Gandy, J. (1978). Attitudes toward the use of restitution. In B. Galaway \& J. Hudson (Eds.), Offender restitution in theory and action (pp. 119-129). Lexington, MA: Lexington Books.

Hough, M., Lewis, H., \& Walker, N. (1988). Factors associated with punitiveness in England and Wales. In N. Walker \& M. Hough (Eds.), Public attitudes to sentencing: Surveys from five countries (pp. 203-217). Aldershot, England: Brookfield.

Hough, M., \& Moxon, D. (1985). Dealing with offenders: Popular opinion and the views of victims. The Howard Journal of Criminal Justice, 24, 160-175.

Huey, S.J., Henggeler, S.W., Brondino, M.J., \& Pickrel, S.G. (2000). Mechanisms of change in multisystemic therapy: Reducing delinquent behavior through therapist adherence and improved family and peer functioning. Journal of Consulting and Clinical Psychology, 68, 451-467.

Lambie, I., Ioane, J., \& Best, C. (2014). 17 year olds and youth justice. New Zealand Law Journal, 8, 316-320.

Langworthy, R.H., \& Whitehead, J.T. (1986). Liberalism and fear as explanations of punitiveness. Criminology, 24, 575-591.

Lee, A. (1996). Public attitudes towards restorative justice. In B. Galaway \& J. Hudson (Eds.), Restorative justice: International perspectives (pp. 337-347). Monsey, NY: Criminal Justice Press.

Lipsey, M.W. (2009). The primary factors that characterize effective interventions with juvenile offenders: A meta-analytic overview. Victims \& Offenders, 4, 124-147.

Lipsey, M.W., \& Cullen, F.T. (2007). The effectiveness of correctional rehabilitation: A review of systematic reviews. Annual Review of Law and Social Science, 3, 297-320.

Loeber, R., \& Farrington, D.P. (1998). Serious and violent juvenile offenders: Risk factors and successful interventions. London: Sage Publications.

Maruna, S., \& King, A. (2009). Once a criminal, always a criminal?: 'Redeemability' and the psychology of punitive public attitudes. European Journal on Criminal Policy and Research, $15,7-24$.

Ministry of Justice. (2014). Reoffending analysis for restorative justice cases 2008-2011. Wellington, NZ: Author. Retrieved from https:/www.justice.govt.nz/assets/Documents/ Publications/rj-Reoffending-Analysis-for-RestorativeJustice-Cases-2008-2013-Summary-Results.pdf.

Ouimet, M., \& Coyle, E.J. (1991). Fear of crime and sentencing punitiveness: Comparing the general public and court practitioners. Canadian Journal of Criminology, 33, 149-172.

Piquero, A.R., Cullen, F.T., Unnever, J.D., Piquero, N.L., \& Gordon, J.A. (2010). Never too late: Public optimism about juvenile rehabilitation. Punishment \& Society, 12, 187-207.

Piquero, A.R., \& Steinberg, L. (2009). Public preferences for rehabilitation versus incarceration of juvenile offenders. Journal of Criminal Justice, 38, 1-6.

Pratt, J. (2007). Penal populism. London and New York: Routledge.

Pratt, J., \& Clark, M. (2005). Penal populism in New Zealand. Punishment \& Society, 7, 303-322.

Roberts, J.V. (2004). Public opinion and youth justice. Crime and Justice, 31, 495-542.

Roper, T., \& Thompson, A. (2006). Estimating the costs of crime in New Zealand in 2003/04. (Report No. 06/04). Wellington, New Zealand: New Zealand Treasury. Retrieved from https://reasury.govt.nz/sites/default/files/2007-09/twp0604.pdf

Rowe, M. (2013). Perceptions of fear of crime and punitivity in New Zealand. In Helmut Kury \& J. Winterdyk (Eds.), Fear of crime and punitiveness: Results from international student surveys (vol. 9, p. 81). Brockmeyer Verlag.

Rübsamen, N., Akmatov, M.K., Castell, S., Karch, A., \& Mikolajczyk, R.T. (2017). Comparison of response patterns in different survey designs: A longitudinal panel with mixedmode and online-only design. Emerging Themes in Epidemiology, 14, 4 .

Schwartz, I.M., Guo, S., \& Kerbs, J.J. (1992). Public attitudes toward juvenile crime and juvenile justice: Implications for public policy. Hamline Journal of Public Law \& Policy, 13, 241-262.

Scott, E.S., Reppucci, N.D., Antonishak, J., \& DeGennaro, J.T. (2006). Public attitudes about the culpability and punishment of young offenders. Behavioral Sciences \& the Law, 24, 815-832.

Scott, S. (2008). An update on interventions for conduct disorder. Advances in Psychiatric Treatment, 14, 61-70.

Sexton, T.L., \& Alexander, J.F. (2002). Family-based empirically supported interventions. The Counseling Psychologist, 30, 238-261.

Spiranovic, C.A., Roberts, L.D., \& Indermaur, D. (2012). What predicts punitiveness? An examination of predictors of punitive attitudes towards offenders in Australia. Psychiatry, Psychology and Law, 19, 249-261.

Thakker, J. (2012). Public attitudes to sex offenders in New Zealand. Journal of Sexual Aggression, 18, 149-163.

Thomas, D.R. (2006). A general inductive approach for analyzing qualitative evaluation data. American Journal of Evaluation, 27, 237-246.

Wood, J., \& Viki, G.T. (2004). Public perceptions of crime and punishment. In J.R. Adler (Ed.), Forensic psychology: 
Concepts, debates and practice (pp. 16-36). Cullompton, UK: Willan Publishing.

Yoshikawa, H. (1994). Prevention as cumulative protection: Effects of early family support and education on chronic delinquency and its risks. Psychological Bulletin, 115, 28-54.
Zarafonitou, C. (2011). Punitiveness, fear of crime and social views. In H. Kury \& E. Shea (Eds.), Punitivity international developments (vol. 2, pp. 269-294). Bochum, Germany: Brockmeyer Verlag University Press.

Zehr, H. (2005). Changing lenses: A new focus for crime and justice. Scottsdale, PA: Herald Press. 